\title{
A Pediatric Intensive Care Unit Bedside Computer Clinical Decision Support Protocol for Hyperglycemia Is Feasible, Safe and Offers Advantages
}

\author{
Eliotte L. Hirshberg, MD, MS, ${ }^{1-4}$ Michael J. Lanspa, MD, MS,, ${ }^{1,3}$ Emily L. Wilson, MS,1,2 \\ Katherine A. Sward, $\mathrm{PhD}_{1}^{5,6}$ Al Jephson, MS, Gitte Y. Larsen, MD, MS, \\ and Alan H. Morris, MD ${ }^{1,3,5}$
}

\begin{abstract}
Background: Computer clinical decision support (CDS) systems are uncommon in the pediatric intensive care unit (PICU), despite evidence suggesting they improve outcomes in adult ICUs. We reasoned that a bedside CDS protocol for intravenous insulin titration, eProtocol-insulin, would be feasible and safe in critically ill children. Methods: We retrospectively reviewed data from non-diabetic children admitted to the PICU with blood glucose (BG) $\geq 140 \mathrm{mg} / \mathrm{dL}$ who were managed with intravenous insulin by either unaided clinician titration or eProtocol-insulin. Primary outcomes were BG measurements in target range $(80-110 \mathrm{mg} / \mathrm{dL})$ and severe hypoglycemia (BG $\leq 40 \mathrm{mg} / \mathrm{dL}$ ); secondary outcomes were 60-day mortality and PICU length of stay. We assessed bedside nurse satisfaction with the eProtocol-insulin protocol by using a 5-point Likert scale and measured clinician compliance with eProtocol-insulin recommendations.

Results: Over 5 years, 69 children were titrated with eProtocol-insulin versus 104 by unaided clinicians. eProtocol-insulin achieved target range more frequently than clinician titration $(41 \%$ vs. $32 \%, P<0.001)$. Severe hypoglycemia was uncommon in both groups (4.3\% of patients in eProtocol-insulin, $8.7 \%$ in clinician titration, $P=0.37$ ). There were no differences in mean time to $\mathrm{BG}$ target or median $\mathrm{BG}$ between the groups. Mortality was $23 \%$ in both groups. Clinician compliance with eProtocol-insulin recommendations was $89 \%$. Nurses believed that eProtocol-insulin was easy to understand and safer than clinician titration.

Conclusions: eProtocol-insulin is safe for titration of intravenous insulin in critically ill children. Clinical research protocols and quality improvement initiatives aimed at optimizing BG control should utilize detailed computer protocols that enable replicable clinician decisions.
\end{abstract}

Keywords: Computer, Decision support, Pediatric, Hyperglycemia, Glucose, Protocol.

\section{Introduction}

$\mathbf{S}^{\mathrm{s}}$ RESS HYPERGLYCEMIA IS common in critically ill children and is associated with increased harm. ${ }^{1-5}$ The optimal approach to blood glucose (BG) control in children remains uncertain. ${ }^{6-10}$ Although enthusiasm for titration of insulin to achieve a target BG of $80-110 \mathrm{mg} / \mathrm{dL}$ had shifted in the adult community, the question has not been answered for a mixed pediatric population. Fear of hypoglycemia prevents many pediatric clinicians from using intravenous insulin titration protocols. ${ }^{11}$ Of utmost importance to appropriate BG control is the demonstration of a safe, feasible, and practical method for minimizing hypoglycemia. ${ }^{11-13}$

In the adult intensive care unit (ICU), the use of computer clinical decision support (CDS) for BG control results in more consistent BG target levels and fewer adverse events than do paper protocols. ${ }^{14-16}$ To optimize BG control, investigators have implemented bedside paper protocols or

\footnotetext{
${ }^{1}$ Pulmonary and Critical Care Division, and ${ }^{2}$ Center for Humanizing ${ }_{5}$ Critical Care, Intermountain Medical Center, Murray, Utah.

${ }^{3}$ Pulmonary and Critical Care Medicine, ${ }^{4}$ Pediatric Critical Care, and ${ }^{5}$ Department of Biomedical Informatics, University of Utah School of Medicine, Salt Lake City, Utah.

${ }^{6}$ University of Utah School of Nursing, Salt Lake City, Utah.
} 
guidelines for intravenous insulin titration in the pediatric ICU (PICU). ${ }^{17-19}$ However, CDS protocol use in the PICU is not widely accepted. ${ }^{20-22}$ Clinicians express concern about both the introduction of unseen risk and alienation from bedside decision making. ${ }^{23-25}$ Workflow burden and excessive time consumption are other stated barriers to bedside CDS implementation. ${ }^{26}$ Ironically, it is excessive physician burden, and the associated information overload, that justifies CDS use. ${ }^{26-28}$

Detailed CDS protocols enable replicable physician decisions, can provide personalized patient care recommendations, and can lessen physician cognitive burden. ${ }^{26-31}$ In the adult ICU, eProtocol-insulin use resulted in superior achievement of the BG target with excellent clinician compliance (95\%). ${ }^{16,32}$ We modified eProtocol-insulin interface and insulin dose display recommendations for use in children and implemented eProtocol-insulin in the PICU. We used the same rules as used in the adult ICU. ${ }^{16,32}$ We compared patients who received IV insulin therapy by unaided clinician titration (clinician titration) with those managed with eProtocol-insulin (eProtocolinsulin) to evaluate safety and feasibility of this CDS tool in the PICU.

\section{Methods}

We performed a retrospective descriptive cohort analysis of hyperglycemic ( $\mathrm{BG} \geq 140 \mathrm{mg} / \mathrm{dL}[7.8 \mathrm{mmol} / \mathrm{L}]$ ) PICU patients who received intravenous insulin and were admitted between January 2003 and January 2008 (Fig. 1). Institutional review boards approved the study with a waiver of informed consent (University of Utah 00013681; Intermountain Healthcare 1008548). We compared treatment without a protocol or unaided clinician titration (clinician titration) with titration with a detailed, context-sensitive computer protocol that generated personalized care recommendations (eProtocol-insulin) $(\mathrm{NIH}-$

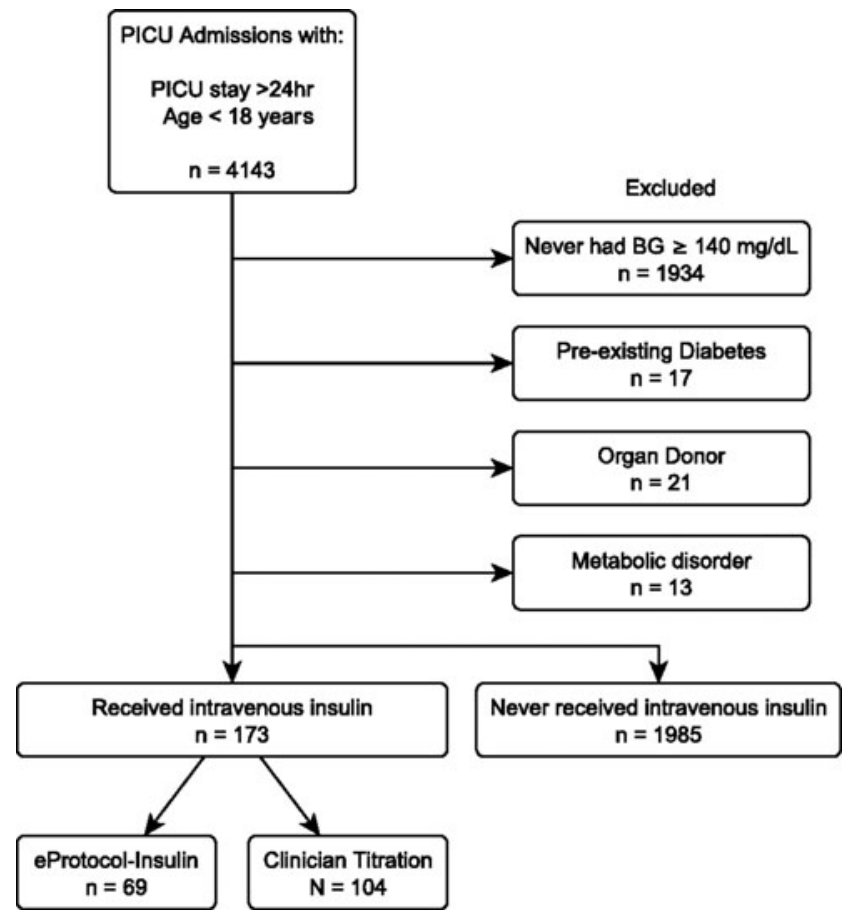

FIG. 1. Inclusion diagram for comparison cohort. roadmap contract No. HHSN268200425210C); the rules and algorithm for eProtocol-insulin are published in the Supplementary Appendix A (Supplementary Data are available online at www.liebertpub.com/dia). ${ }^{16}$ For the pediatric version, every eProtocol-insulin recommendation was followed with a physician or licensed nurse practitioner order.

\section{Study site and subject selection}

We included children $<18$ years old who remained in the PICU for $\geq 24 \mathrm{~h}$, had at least one BG $\geq 140 \mathrm{mg} / \mathrm{dL}$, and were treated with intravenous insulin. All patients were admitted to a $26-32$ bed PICU (2000 admissions/year) within a $242-248$ bed, university-affiliated, tertiary care pediatric hospital. PICU clinicians treated hyperglycemia with a BG target range of their choice for the entire study period. At the time of the study, there was not only enthusiasm for an $80-110 \mathrm{mg} / \mathrm{dL}$ target range but also concern about hypoglycemia, and, thus, a target range of $80-140 \mathrm{mg} / \mathrm{dL}$ was sometimes chosen. For the first half of the study period, insulin titration was directed by unaided clinician titration; for the second half of the study period, eProtocol-insulin was used. We focus the discussion on the $80-110 \mathrm{mg} / \mathrm{dL}$ BG target range but report relevant outcomes for both BG target ranges, since the BG target range chosen by the clinician was not recorded in the clinician titration group. For patients with multiple PICU admissions during the study period, we included only the first admission. We excluded patients who might have received insulin for diagnoses other than stress hyperglycemia (patients with diagnoses of diabetes, primary hypoglycemia, or medium-chain acyl-CoA dehydrogenase deficiency [ICD-9 codes: 250.00-250.03, 250.10-250.13, 250.31-250.33, 251.0-251.2, 775.6, 775.0, 270.3]).

\section{Data collection}

Data were obtained from the highly detailed Intermountain Healthcare Electronic Medical Record. Receipt of intravenous insulin was confirmed by a manual review of the chart. In addition to demographic data, we calculated the PRISM III score based on the first $12 \mathrm{~h}$ of PICU admission to determine illness severity. ${ }^{33}$ We included BG values obtained from blood gas labs, bedside point of care, and clinical labs. If two or more BG values were obtained within $15 \mathrm{~min}$ of one another, only the first value was retained for the analysis. We calculated how long it took from the initiation of insulin to achieve target range BG (80-110 and $80-140 \mathrm{mg} / \mathrm{dL})$ and what percent of readings during the first $120 \mathrm{~h}$ (5 days) were within target range. We assessed how many patients had at least one BG value $\leq 70 \mathrm{mg} /$ dL ("mild hypoglycemia") or $\leq 40 \mathrm{mg} / \mathrm{dL}$ ("severe hypoglycemia"). Because of known inaccuracies of low point-of-care $B G$ values, we verified that all $B G$ values $\leq 40 \mathrm{mg} / \mathrm{dL}$ were confirmed with a serum measurement at the same time. We calculated 60-day mortality and hospital- and PICU lengths of stay. We assessed bedside nurse satisfaction with a short survey of eProtocol-insulin based on a 5-point Likert scale (Supplementary Appendix B).

\section{Statistical analysis}

We compared the descriptive statistics and clinical outcome rates of the eProtocol-insulin and clinician titration groups. We compared central tendency with Wilcoxon rank- 
sum tests and proportions with chi-square and Fisher's exact tests. We adjusted the alpha level of statistical significance (0.05) for multiple comparisons (Bonferroni). We also fit a univariate logistic regression to assess the overall association between severe hypoglycemia and 60-day mortality.

\section{Results}

\section{Demographics}

Of the 2158 PICU patients, $173(8 \%)$ were treated with intravenous insulin. We observed no differences in baseline characteristics or in antecedent hyperglycemia between eProtocol-insulin $(n=69)$ and clinician titration $(n=104)$ groups (Table 1).

Both eProtocol-insulin and clinician titration groups had similar BG values (median 116 vs. $118 \mathrm{mg} / \mathrm{dL}$, respectively, $P=0.34$ ), and time to the first BG value within target (10 vs. $12 \mathrm{~h}, P=0.22$ for $80-110 \mathrm{mg} / \mathrm{dL} ; 7$ vs. $6 \mathrm{~h}, P=0.74$ for 80 $140 \mathrm{mg} / \mathrm{dL}$ ). However, during the first $120 \mathrm{~h}$ of intravenous insulin administration, we observed a significant difference in the percentage of BG values within both target ranges (for
$80-110 \mathrm{mg} / \mathrm{dL}: 41 \%$ of eProtocol-insulin group, $32 \%$ of clinician titration group, $P<0.001$; for $80-140 \mathrm{mg} / \mathrm{dL}$ : $68 \%$ of eProtocol-insulin group, $62 \%$ of clinician titration group, $P<0.001)$. A total of nine patients did not achieve a BG value within the $80-110 \mathrm{mg} / \mathrm{dL}$ target range (one eProtocol-insulin group, eight clinician titration groups).

The distribution of BG values in both eProtocol-insulin and clinician titration groups is shown in Figure 2. We observed no statistically significant difference between the eProtocol-insulin and clinician titration groups for mild hypoglycemia ( $64 \%$ vs. $56 \%, P=0.34)$. We observed no significant difference in occurrence of severe hypoglycemic BG values $(0.08 \%$ in eProtocol-insulin vs. $0.20 \%$ in clinician titrated, $P=0.13$ ), nor the percentage of patients who experienced severe hypoglycemia $(4.3 \%$ vs. $8.7 \%, P=0.37)$. For comparison, $3.4 \%$ of the patients who did not receive intravenous insulin had a severely hypoglycemic BG value. In the eProtocol-insulin group, clinicians chose the $80-110 \mathrm{mg} / \mathrm{dL}$ target $90 \%$ of the time, and patients received an average (SD) of $0.07(0.06) \mathrm{U} /(\mathrm{kg} \cdot \mathrm{h})$ of insulin with a mean duration of insulin infusion of 4.1 days.

Table 1. Baseline Characteristics, Blood Glucose Metrics, and Clinical Outcomes of eProtocol-Insulin Versus Clinician Titration Groups

\begin{tabular}{|c|c|c|c|}
\hline & $\begin{array}{l}\text { eProtocol-insulin } \\
\quad(\mathrm{n}=69)\end{array}$ & $\begin{array}{l}\text { Clinician titration } \\
\quad(\mathrm{n}=104)\end{array}$ & $\mathrm{P}$ value \\
\hline \multicolumn{4}{|l|}{ Baseline characteristics } \\
\hline Age (years); median (IQR) & $3(1-13)$ & $3(1-12)$ & 0.42 \\
\hline PRISM score; median (IQR) & $11(7-16)$ & $9(4-15)$ & 0.10 \\
\hline$\%$ female & $54 \%$ & $44 \%$ & 0.29 \\
\hline$\%$ diagnostic category & & & 0.28 \\
\hline Cardiac surgery & $23 \%$ & $21 \%$ & \\
\hline General surgery & $9 \%$ & $9 \%$ & \\
\hline Medical diagnosis & $55 \%$ & $45 \%$ & \\
\hline Trauma & $13 \%$ & $25 \%$ & \\
\hline Maximum blood glucose before receiving insulin (mg/dL) & $302(251-438)$ & $282(231-378)$ & 0.14 \\
\hline \multicolumn{4}{|l|}{ Blood glucose metrics } \\
\hline Median blood glucose during PICU stay (mg/dL) & $116(107-126)$ & $118(108-134)$ & 0.34 \\
\hline Median blood glucose day 1 of insulin (mg/dL) & $133(115-155)$ & $128(111-156)$ & 0.67 \\
\hline Median blood glucose day 2 of insulin (mg/dL) & $106(98-119)$ & $113(100-133)$ & 0.09 \\
\hline Median blood glucose day 3 of insulin (mg/dL) & $105(93-120)$ & $111(100-134)$ & 0.13 \\
\hline Median blood glucose day 4 of insulin (mg/dL) & $112(101-121)$ & $111(99-134)$ & 0.71 \\
\hline Median blood glucose day 5 of insulin $(\mathrm{mg} / \mathrm{dL})$ & $106(98-118)$ & $113(97-129)$ & 0.32 \\
\hline $\begin{array}{l}\% \text { blood glucose values in range (between } 80 \text { and } \\
110 \mathrm{mg} / \mathrm{dL} \text { ) during first } 120 \mathrm{~h}\end{array}$ & $41 \%$ & $32 \%$ & $<0.001$ \\
\hline $\begin{array}{l}\% \text { blood glucose values in range (between } 80 \text { and } \\
140 \mathrm{mg} / \mathrm{dL} \text { ) during first } 120 \mathrm{~h}\end{array}$ & $68 \%$ & $62 \%$ & $<0.001$ \\
\hline $\begin{array}{l}\text { Time from initiation of IV insulin to first blood } \\
\text { glucose within range }[80-110 \mathrm{mg} / \mathrm{dL}](\mathrm{h})^{\mathrm{a}}\end{array}$ & $10(6-20)$ & $12(7-26)$ & 0.22 \\
\hline $\begin{array}{l}\text { Time from initiation of IV insulin to first blood } \\
\text { glucose within range }[80-140 \mathrm{mg} / \mathrm{dL}](\mathrm{h})^{\mathrm{b}}\end{array}$ & $7(3-13)$ & $6(3-13)$ & 0.74 \\
\hline$\%$ of patients ever $\leq 70 \mathrm{mg} / \mathrm{dL}$ & $64 \%$ & $56 \%$ & 0.3446 \\
\hline$\%$ of patients ever $\leq 40 \mathrm{mg} / \mathrm{dL}$ & $4 \%$ & $9 \%$ & 0.3666 \\
\hline \multicolumn{4}{|l|}{ Clinical outcomes } \\
\hline$\%$ 60-day mortality & $23 \%$ & $23 \%$ & 1.00 \\
\hline Hospital length of stay (days) & $15.2(7.2-32.2)$ & $18.4(9.8-32.0)$ & 0.45 \\
\hline PICU length of stay (days) & $9.8(4.1-16.7)$ & $10.2(5.5-14.8)$ & 0.97 \\
\hline
\end{tabular}

${ }^{\mathrm{a}}$ Nine patients did not achieve glucose control $(80-110 \mathrm{mg} / \mathrm{dL})$ : eight from the clinician titration group and one from the eProtocol-insulin group.

${ }^{\mathrm{b}}$ Three patients did not achieve glucose control $(80-140 \mathrm{mg} / \mathrm{dL})$ : two from the clinician titration group and one from the eProtocol-insulin group.

PICU, pediatric intensive care unit. 


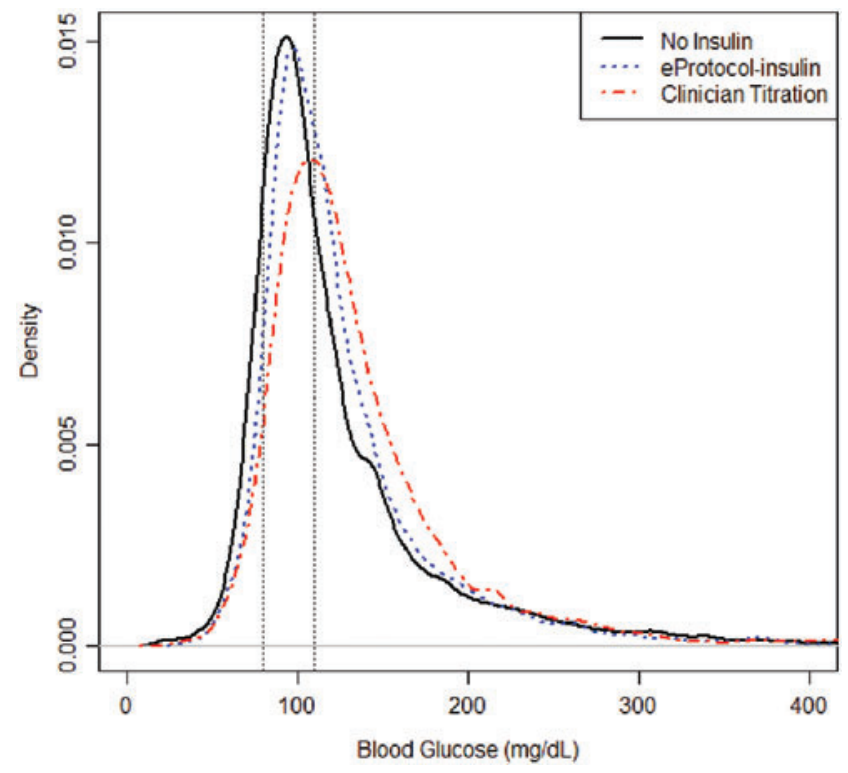

FIG. 2. Distribution of all blood glucose values in pediatric intensive care unit for eProtocol-insulin versus clinician titration (values from patients who met inclusion criteria but did not receive insulin are also displayed for reference).

We observed no difference in mortality or PICU length of stay between eProtocol-insulin and clinician titration groups (Table 1). BG values were rarely $\leq 40 \mathrm{mg} / \mathrm{dL}$, and this was not associated with mortality (univariate logistic regression Odds Ratio $0.468, P=0.49$ ).

\section{eProtocol-insulin compliance}

Clinician compliance with overall eProtocol-insulin recommendations was high, with $89 \%$ of recommendations accepted. Compliance with eProtocol-insulin recommendations was highest $(92 \%)$ when the BG value was between 80 and $110 \mathrm{mg} / \mathrm{dL}$ and lowest (71\%) when the BG value was below $60 \mathrm{mg} / \mathrm{dL}$. Common reasons for non-compliance with eProtocol-insulin included administration of medications that interfere with insulin and glucose delivery, as well as physician disagreement with the recommendation. Technical problems with the computer were listed infrequently. A complete list of reasons for non-compliance are provided in the Supplementary Appendix C.

\section{Nurse-rated feasibility and satisfaction}

In general, nurses rated eProtocol-insulin on a Likert scale of 1 (disagree) to 5 (agree) as easy to understand (mean [SD]: 4.27 [0.59]) with clear recommendations (4.21 [0.89]). Nurses perceived eProtocol-insulin as slightly safer (3.85 [0.69]) than clinician titration and perceived it to be associated with less hypoglycemia (3.57 [0.85]).

\section{Discussion}

eProtocol-insulin, a bedside CDS protocol for insulin titration in the PICU, performs similarly, and more favorably in some regards, than clinician titration of insulin for the management of hyperglycemia in the PICU. eProtocolinsulin with a target of 80-110 or 80-140 mg/dL was safe and associated with a hypoglycemia rate similar to the rate in patients not receiving intravenous insulin. eProtocol-insulin facilitated collection of granular data (insulin dose, clinician chosen BG target) and enabled calculation of clinician compliance with protocol recommendations.

Our experience with a CDS protocol in the PICU reinforces objectives and goals outlined by Timbie et al. These include prioritizing clinician specialists' feedback in design and addressing important performance gaps. ${ }^{31}$ eProtocolinsulin use resulted in more BG values in target range; furthermore, all but one patient in the eProtocol-insulin group were able to reach the $80-110 \mathrm{mg} / \mathrm{dL}$ BG target range. Nurse satisfaction with eProtocol-insulin was high, which was consistent with a previous observation that a bedside rounding tool enhanced overall PICU staff satisfaction. ${ }^{34}$

PICU nurses perceived eProtocol-insulin as easy to use, with clear recommendations, safer, and associated with a decreased frequency of hypoglycemia. The latter perception is supported by our results, although the difference in BG value $\leq 40 \mathrm{mg} / \mathrm{dL}$ is not statistically significant. Interestingly, although overall clinician compliance with eProtocol-insulin was high (89\%), compliance with eProtocol-insulin changed based on BG level. This finding provides valuable insight into complex elements surrounding clinician decision making regarding intravenous insulin titration and can help inform future insulin titration protocol development. ${ }^{16,30,32}$ The ability to quantify bedside clinician compliance with an electronic protocol's recommendation is an important benefit of CDS protocols. ${ }^{27,28}$

Compliance with eProtocol-insulin was higher than that noted by Tehrani et al. for a CDS protocol for mechanical ventilation in infants. ${ }^{35}$ Unique features of eProtocol-insulin are its use as both a clinical management protocol for insulin titration and a potential research protocol. eProtocolinsulin facilitates collection of data that might better clarify the clinical and treatment circumstances that contribute to hypoglycemia, rendering a CDS protocol important for scientific rigor. $^{30,32}$ The data from the work we report in this publication were used to inform the design and study procedures for a large prospective multicenter interventional pediatric critical care trial-the National Institutes of Health Heart and Lung Failure Pediatric Insulin Titration Trial (HALF-PINT; U01-HL1-7681). HALF-PINT uses a similar CDS insulin titration protocol based on the proportional integral derivative algorithm. ${ }^{6,36-38}$

Reasons for different compliance with eProtocol-insulin recommendations across $\mathrm{BG}$ values are likely multifactorial. Inferences based on reasons given by the clinician for noncompliance include a desire not to change insulin when the patient is within the BG target. This could be due to the perceived nurse workload or from excessive cognitive burden that limits the ability of clinicians to anticipate the BG if he or she continued the current insulin dose or to predict the appropriate insulin dose if change is indicated. ${ }^{26}$ Bedside clinician patientspecific judgment based on history and the administration of other medications may also contribute. More expansive future analysis of which recommendations were accepted and rejected is likely to be revealing. eProtocol-insulin enabled a preliminary understanding of the interaction between the protocol and the bedside clinician. ${ }^{27,28}$ Our results argue 
against the claim that CDS protocols alienate the clinician from the patient interaction. Our results support the role of CDS tools to augment, not to replace, clinical judgment and to reduce cognitive workload. ${ }^{26,39}$

Our study has several limitations. Our cohort samples are small, and we may have failed to detect clinically meaningful differences in hypoglycemia rates. Detected rates of hypoglycemia will also be dependent on the overall number of BG measurements per day. The clinician titrated group did not have a prescribed protocol for BG measurements, whereas eProtocol-insulin had explicit rules and recommendations. During the first half of the study, patients were treated by unaided clinician titration; during the second half, they were treated with use of ePrtoocol-insulin and we were unable to account for secular changes that may have influenced the treatment of hyperglycemia with insulin. Clinical perspectives regarding the best $\mathrm{BG}$ target also may have changed during the study period. eProtocol-insulin allowed the $\mathrm{BG}$ target range to be specified, whereas the clinician titration group did not. eProtocol-insulin also employed the same calculations and rules for insulin titration regardless of BG target range.

Despite the limitations cited earlier, the use of eProtocolinsulin for the management of hyperglycemia in the PICU is feasible, safe, and easily integrated into clinician work flow as a stand-alone bedside CDS system.

\section{Conclusions}

The eProtocol-insulin CDS protocol was safe, performed similarly to, and offered data collection advantages over clinician titration of IV insulin. Compliance with eProtocolinsulin recommendations was high, and bedside clinicians perceived it favorably. Clinical research protocols and quality improvement initiatives designed to determine preferable BG targets should utilize detailed CDS protocols that enable replicable clinician decisions.

\section{Acknowledgments}

Primary Children's Foundation Award; Intermountain Research and Medical Foundation Grant. Dean Sorenson $\mathrm{PhD}$. Creator/programmer of eProtocol-insulin software.

\section{Authors' Contributions}

Conception (E.L.H., G.Y.L., K.A.S., A.H.M.), data acquisition (E.L.H., A.J., E.W., K.A.S.), data analysis (E.L.H., M.J.L., E.W.), writing the article (E.L.H., M.J.L., A.H.M.), revising the article for important intellectual content (all authors), and approval of final copy (all authors).

\section{Author Disclosure Statement}

No competing financial interests exist.

\section{References}

1. Faustino EV, Apkon M: Persistent hyperglycemia in critically ill children. J Pediatr 2005;146:30-34.

2. Hirshberg E, Larsen G, Van Duker H: Alterations in glucose homeostasis in the pediatric intensive care unit: hyperglycemia and glucose variability are associated with increased mortality and morbidity. Pediatr Crit Care Med 2008;9:361-366.
3. Srinivasan V: Hyperglycemia in the pediatric intensive care unit: a few steps closer to sweetening the pot. Pediatr Crit Care Med 2008;9:231-233.

4. Srinivasan V: Stress hyperglycemia in pediatric critical illness: the intensive care unit adds to the stress! J Diabetes Sci Technol 2012;6:37-47.

5. Wintergerst KA, Buckingham B, Gandrud L, et al.: Association of hypoglycemia, hyperglycemia, and glucose variability with morbidity and death in the pediatric intensive care unit. Pediatrics 2006;118:173-179.

6. Agus MS, Steil GM, Wypij D, et al.: Tight glycemic control versus standard care after pediatric cardiac surgery. N Engl J Med 2012;367:1208-1219.

7. Jeschke MG, Kraft R, Emdad F, et al.: Glucose control in severely thermally injured pediatric patients: what glucose range should be the target? Ann Surg 2010;252:521-527; discussion 7-8.

8. Macrae D, Grieve R, Allen E, et al.: A randomized trial of hyperglycemic control in pediatric intensive care. $\mathrm{N}$ Engl J Med 2014;370:107-118.

9. Macrae D, Tasker RC, Elbourne D: A trial of hyperglycemic control in pediatric intensive care. N Engl J Med 2014; 370:1355-1356.

10. Vlasselaers D, Milants I, Desmet L, et al.: Intensive insulin therapy for patients in paediatric intensive care: a prospective, randomised controlled study. Lancet 2009;373:547-556.

11. Hirshberg EL, Sward KA, Faustino EV, et al.: Clinical equipoise regarding glycemic control: a survey of pediatric intensivist perceptions. Pediatr Crit Care Med 2013;14:123-129.

12. Faustino EV, Bogue CW: Relationship between hypoglycemia and mortality in critically ill children. Pediatr Crit Care Med 2010;11:690-698.

13. Hirshberg E, Lacroix J, Sward K, et al.: Blood glucose control in critically ill adults and children: a survey on stated practice. Chest 2008;133:1328-1335.

14. Eslami S, de Keizer NF, Dongelmans DA, et al.: Effects of two different levels of computerized decision support on blood glucose regulation in critically ill patients. Int $\mathrm{J}$ Med Inform 2012;81:53-60.

15. Mann EA, Jones JA, Wolf SE, Wade CE: Computer decision support software safely improves glycemic control in the burn intensive care unit: a randomized controlled clinical study. J Burn Care Res 2011;32:246-255.

16. Thompson BT, Orme JF, Zheng $\mathrm{H}$, et al.: Multicenter validation of a computer-based clinical decision support tool for glucose control in adult and pediatric intensive care units. J Diabetes Sci Technol 2008;2:357-368.

17. Preissig CM, Hansen I, Roerig PL, Rigby MR: A protocolized approach to identify and manage hyperglycemia in a pediatric critical care unit. Pediatr Crit Care Med 2008;9:581-588.

18. Verhoeven JJ, Brand JB, van de Polder MM, Joosten KF: Management of hyperglycemia in the pediatric intensive care unit; implementation of a glucose control protocol. Pediatr Crit Care Med 2009;10:648-652.

19. Faraon-Pogaceanu C, Banasiak KJ, Hirshberg EL, Faustino EV: Comparison of the effectiveness and safety of two insulin infusion protocols in the management of hyperglycemia in critically ill children. Pediatr Crit Care Med 2010;11:741-749.

20. Mack EH, Wheeler DS, Embi PJ: Clinical decision support systems in the pediatric intensive care unit. Pediatr Crit Care Med 2009;10:23-28.

21. Randolph AG, Pronovost P: Reorganizing the delivery of intensive care could improve efficiency and save lives. J Eval Clin Pract 2002;8:1-8. 
22. Randolph AG, Wypij D, Venkataraman ST, et al.: Effect of mechanical ventilator weaning protocols on respiratory outcomes in infants and children: a randomized controlled trial. JAMA 2002;288:2561-2568.

23. Hunt DL, Haynes RB, Hanna SE, Smith K: Effects of computer-based clinical decision support systems on physician performance and patient outcomes: a systematic review. JAMA 1998;280:1339-1346.

24. Tobin MJ, Jubran A: Meta-analysis under the spotlight: focused on a meta-analysis of ventilator weaning. Crit Care Med 2008;36:1-7.

25. Williams CN, Bratton SL, Hirshberg EL: Computerized decision support in adult and pediatric critical care. World J Crit Care Med 2013;2:21-28.

26. Weber S: Clinical decision support systems and how critical care clinicians use them. J Healthc Inf Manag 2007; 21:41-52.

27. Clemmer TP: Computers in the ICU: where we started and where we are now. J Crit Care 2004;19:201-207.

28. Morris AH: Computerized protocols and bedside decision support. Crit Care Clin 1999;15:523-545, vi.

29. Morris AH: Developing and implementing computerized protocols for standardization of clinical decisions. Ann Intern Med 2000;132:373-383.

30. Morris AH, Orme J, Rocha BH, et al.: An electronic protocol for translation of research results to clinical practice: a preliminary report. J Diabetes Sci Technol 2008;2:802808.

31. Timbie JW, Damberg CL, Schneider EC, Bell DS: A conceptual framework and protocol for defining clinical decision support objectives applicable to medical specialties. BMC Med Inform Decis Mak 2012;12:93.

32. Morris AH, Orme J, Jr., Truwit JD, et al.: A replicable method for blood glucose control in critically Ill patients. Crit Care Med 2008;36:1787-1795.
33. Pollack MM, Patel KM, Ruttimann UE: The Pediatric Risk of Mortality III-Acute Physiology Score (PRISM IIIAPS): a method of assessing physiologic instability for pediatric intensive care unit patients. J Pedaitrics 1997;131: 575-581.

34. Hulyalkar M, Gleich SJ, Kashyap R, et al.: Design and alpha-testing of an electronic rounding tool (CERTAINp) to improve process of care in pediatric intensive care unit. J Clin Monit Comput 2016; doi. 10.1007/s10877-016-9946-1.

35. Tehrani FT, Abbasi S: Evaluation of a computerized system for mechanical ventilation of infants. J Clin Monit Comput 2009;23:93-104.

36. Steil GM, Deiss D, Shih J, et al.: Intensive care unit insulin delivery algorithms: why so many? how to choose? J Diabetes Sci Technol 2009;3:125-140.

37. Steil GM, Langer M, Jaeger K, et al.: Value of continuous glucose monitoring for minimizing severe hypoglycemia during tight glycemic control. Pediatr Crit Care Med 2011; 12:643-648.

38. Steil GM, Rebrin K: Closed-loop insulin delivery-What lies between where we are and where we are going? Expert Opin Drug Deliv 2005;2:353-362.

39. Avansino J, Leu MG: Effects of CPOE on provider cognitive workload: a randomized crossover trial. Pediatrics 2012;130:e547-e552.

Address correspondence to: Eliotte L. Hirshberg, MD, MS Shock Trauma ICU Intermountain Medical Center 5121 S. Cottonwood Street Murray, UT 84107

E-mail: ellie.hirshberg@imail.org; or ellie.hirshberg@hsc.utah.edu 